\title{
Calculation Software and Safety Analysis for Live Working of $\pm 800 k V$ Qishao Ultra High Voltage Transmission Line
}

\author{
Zhigang Wang ${ }^{1,2,3}$, Hao Guo ${ }^{1,2,3}$, Mingming Qiao ${ }^{1,2,3}$, Zhaohui Zhen ${ }^{1,2,3}$, Peng Li ${ }^{1,2,3 *}$ \\ ${ }^{1}$ Live Line Operation Center, Power Transmission Maintenance Branch of State Grid Hunan Electric Power Co., Ltd., ChangSha, Hunan, \\ China \\ ${ }^{2}$ Intelligent live working technology equipment (robot) Hunan Provincial Key Laboratory, ChangSha, Hunan, China \\ ${ }^{3}$ Live inspection and intelligent operation technology State Grid Corporation Laboratory, ChangSha, Hunan, China
}

\begin{abstract}
In the power system, live workers need to complete various tasks such as heat treatment of the draft plate in a strong electric field. The inaccurate estimation of the wire load increases the labor load of the operators and can cause safety accidents such as wire disconnection and grounding short-circuit. This paper proposes a set of simple and easy-to-use live working mechanics calculation software to assist the dynamic analysis of the live working load of transmission lines, rationally select working tools, and improve the safety of live working.
\end{abstract}

\section{Introduction}

In the power system, live work is a special work with "high risk, high altitude, high voltage, and high technology". Live workers need to complete various tasks in a strong electric field, such as insulator replacement, hardware replacement, wire repair, foreign body removal, and heat treatment of the drainage plate. Therefore, engineers and technicians engaged in live work need to have knowledge of both electricity and mechanics. Before each operation, the engineer needs to calculate the electrical safety distance and line mechanics according to the on-site operation situation to demonstrate the feasibility of this work and form an operation plan to guide the work.

However, traditional calculation methods may cause incorrect calculation results due to their approximation and complexity. Inaccurate estimation of wire force (vertical gravity or horizontal pulling force) results in the selection of tools that are too large or too small, which increases the labor load of the operators. Furthermore, due to the huge workload of traditional calculation methods, work efficiency is seriously reduced. When urgent repair operations are needed, the emergency response time is extended.

Therefore, it is necessary to develop a set of easy-touse, accurate analysis and calculation results of live work safety analysis and mechanical calculation software. The software can calculate the electrical and mechanical parameters of live working lines on transmission lines. The feasibility of the operation can be analyzed, and the operation tools can be selected reasonably. It can improve the safety and work efficiency of live working, which is of great significance to the majority of live working personnel.

\section{Functions and principles of the software}

The working conditions are carried out under normal weather, no ice is required, and the wind speed is not greater than five levels.

In the relevant calculations, only the weight of the wires and fittings and the load caused by wind pressure are considered

\subsection{Force calculation of linear tower}

\subsubsection{Self-weight load of transmission wire $g_{1}$}

$$
g_{1}=\frac{G_{0}}{S}
$$

$g_{0}$-wire weight per kilometer $(\mathrm{kg} / \mathrm{km}), \quad S$ The entire cross-sectional area of the wire.

\subsubsection{Wind pressure $P$}

The wind pressure on the wire is caused by air movement energy. The horizontal wind pressure in the vertical line direction is:

$$
P=\alpha K F \frac{V^{2}}{16} \sin ^{2} \theta(9.8 \mathrm{~N})
$$

$\alpha$-coefficient of uneven wind speed 1.0, wind speed $10 \mathrm{~m} / \mathrm{s}, F$-The projection surface of the wind surface on a plane perpendicular to the wind direction, $\theta$ The horizontal angle between the wind direction and the wind

*Corresponding author's e-mail: lipeng $@$ stu.hut.edu.cn 
projection surface, When calculating, consider that the wind direction is perpendicular to the direction of the power line $\sin ^{2} \theta=1, K$-Aerodynamic coefficient 1.1 .

\subsubsection{Comprehensive ratio}

$$
g_{6}=\sqrt{g_{1}^{2}+g_{4}^{2}}
$$

\subsubsection{Vertical load on the insulator string}

$$
Q=g_{1} S l_{\mathrm{z}}+W
$$

Where K Including spacer rods, pull plates, wire clamps and the weight of the equipotential operator, it is approximately $200 \mathrm{~kg}$ (the weight of composite insulators is not considered, $\pm 800 \mathrm{kV}$ UHV lines are six-split conductors)

\subsubsection{Horizontal load on the insulator string}

$$
P=g_{4} S l_{\mathrm{p}}
$$

\subsubsection{The total load on the insulator string is}

$$
G=\sqrt{Q^{2}+P^{2}}
$$

\subsubsection{Total load on a single sub-conductor is}

$$
G_{1}=G / \mathrm{n}
$$

where $\mathrm{n}$ is the number of split wires, unit root.

\subsection{Calculation and Analysis of Forces on Tension Insulator Replacement}

Suppose the temperature under known meteorological conditions is $t_{m}$, the specific load is $g_{m}$, the stress is $\theta_{m}$, and the temperature under the meteorological conditions to be determined is $t_{n}$, the specific load is $g_{n}$, and the stress is $\theta_{n}$, then the wire state equation is

$$
\sigma_{\mathrm{n}}-\frac{g_{\mathrm{n}}^{2} l^{2}}{24 \beta \sigma_{\mathrm{n}}^{2}}=\sigma_{\mathrm{m}}-\frac{g_{\mathrm{m}}^{2} l^{2}}{24 \beta \sigma_{\mathrm{m}}^{2}}-\frac{\alpha}{\beta}\left(t_{\mathrm{n}}-t_{\mathrm{m}}\right)
$$

The tensile force of the insulator is $T=\theta_{n} S$.

where: $\alpha$ - the thermal expansion coefficient of the wire; $\beta$-the elastic elongation coefficient of the wire, $154 \times 10^{-6}\left(\mathrm{~mm}^{2} / 9.8 \mathrm{~N}\right) ; l$-represents the span $(\mathrm{m})$.

\subsection{Force when handling wire and ground wire broken strands}

According to the conductor stress, specific load and air temperature before and after the unmounted ladder (flying car), the following state equation is used to calculate the conductor stress after the flying car is suspended.

$$
\sigma_{1}-\frac{l_{D}^{2} g^{2} E}{24 \sigma_{1}^{2}}-\alpha E\left(t_{2}-t_{1}\right)
$$

The sag of the ground wire of the suspension ladder (flying vehicle) in the continuous gear can be calculated by the following formula.

$$
f_{x}=\frac{x\left(l_{x}-x\right) g}{2 \sigma_{2} \cos \phi_{x}}+\frac{x\left(l_{x}-x\right) Q^{\prime}}{l_{x} \sigma_{2} s \cos ^{2} \phi_{x}}
$$

\section{Safety distance analysis}

According to different operation methods, workers choose different paths to enter the electric field. According to the provisions of Q/GDW1799.2-2013 "State Grid Corporation of Electric Power Safety Work Regulations Line Part", the safe distance between the operator and the live body during live work shall not be less than $6.8 \mathrm{~m}$; the safe distance between the equipotential personnel and the grounding body should not be Less than $6.8 \mathrm{~m}$. The combined gap of operators during the process of entering the electric field shall not be less than $6.6 \mathrm{~m}$. Therefore, it is necessary to calculate and verify the safety distances and combined gaps of different work methods to meet the requirements to carry out live work.

\subsection{Calculation process}

Comparing the content of the work items, tool selection and analysis and calculation process, etc., the frequently carried out work items are divided into 5 categories. Each type of research content and technical route are as follows.

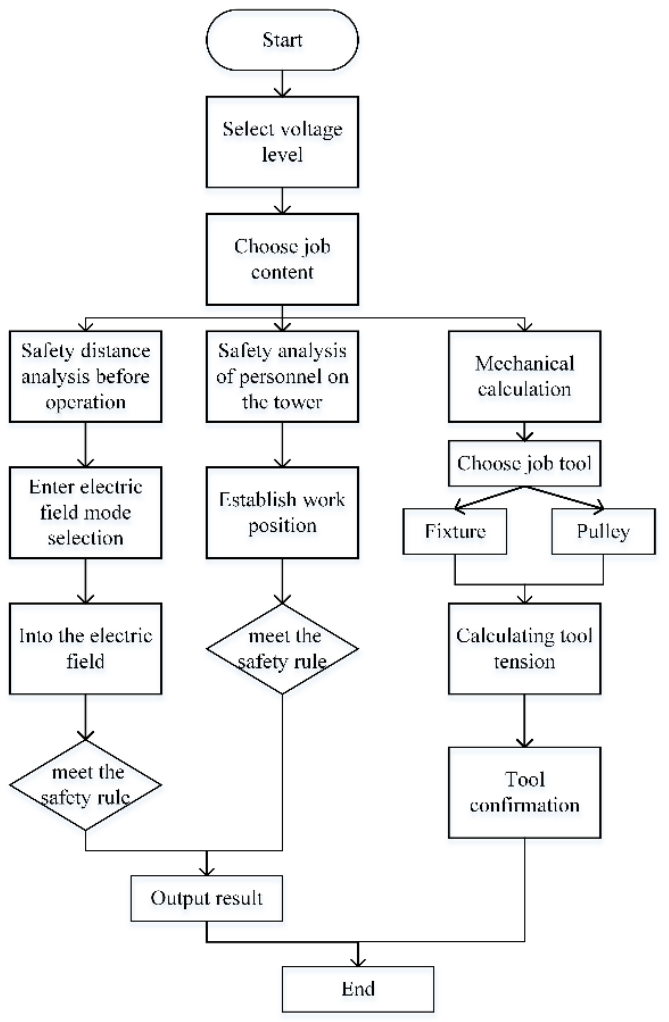

Fig. 1. Replacement of I string single chip, entire string of insulators, and suspension clamps 


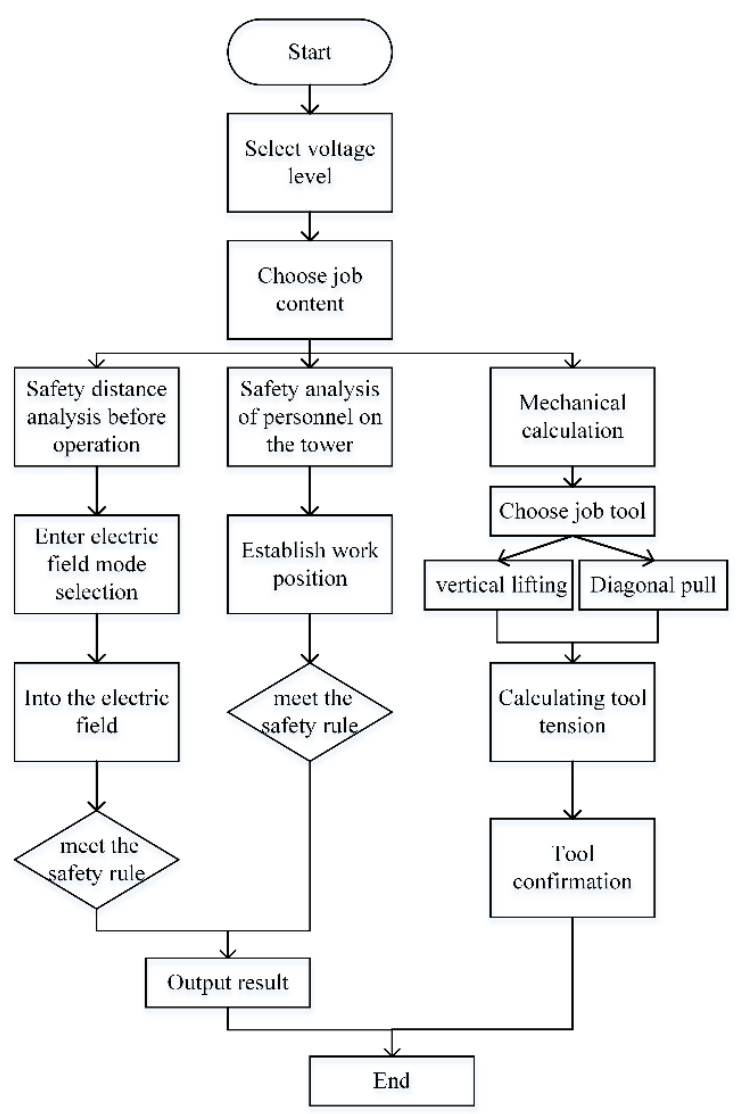

Fig. 2. Replacement of V-string and L-string single-chip and entire string insulators

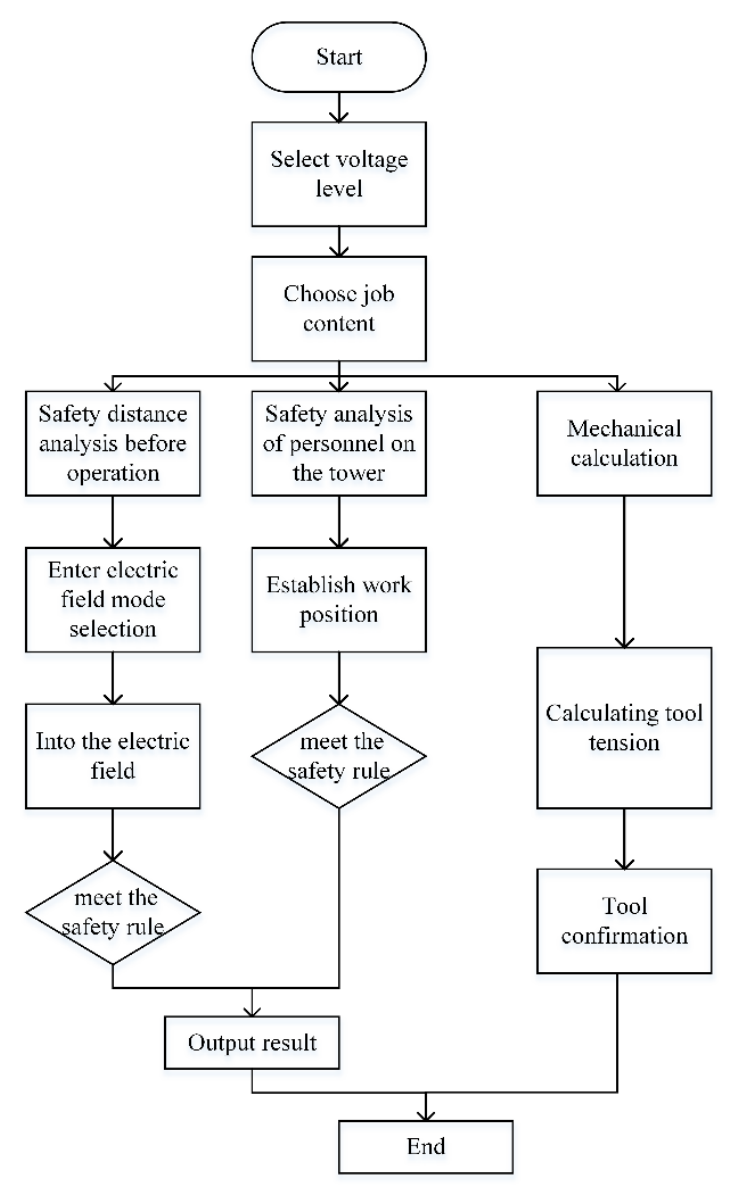

Fig. 3. Replacement of tensile single piece and entire string of insulators

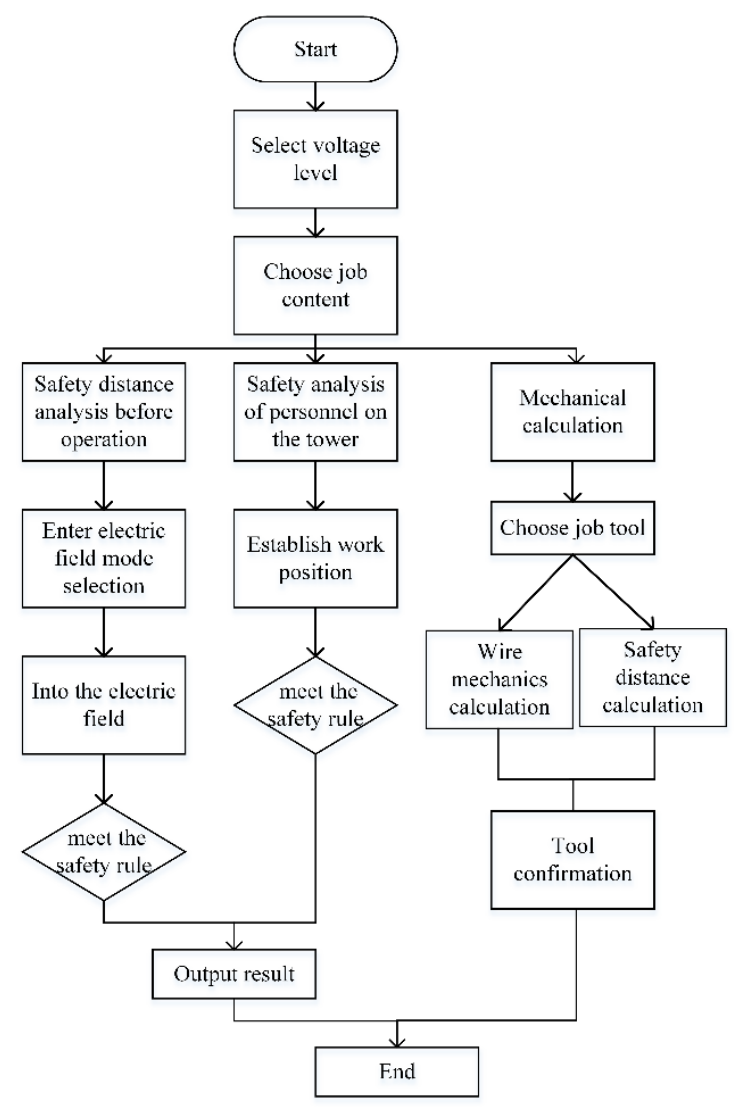

Fig. 4. Repair guide and ground wire operation 


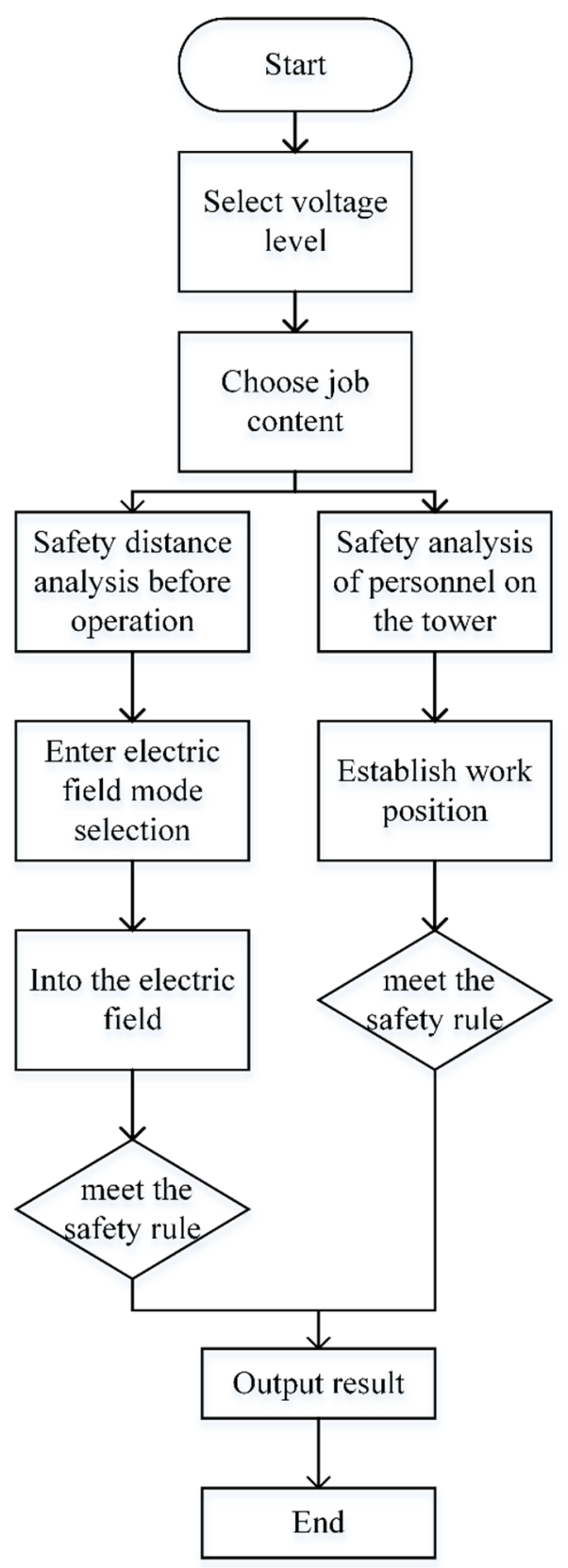

Fig. 5. Replacement of spacer rods, anti-vibration/anti-dance devices, treatment of heating of the drainage plate and falling off of fittings

\subsection{Computing software interface}

According to the calculation principle and calculation process, the calculation software is compiled, and the design function interface is as follows.

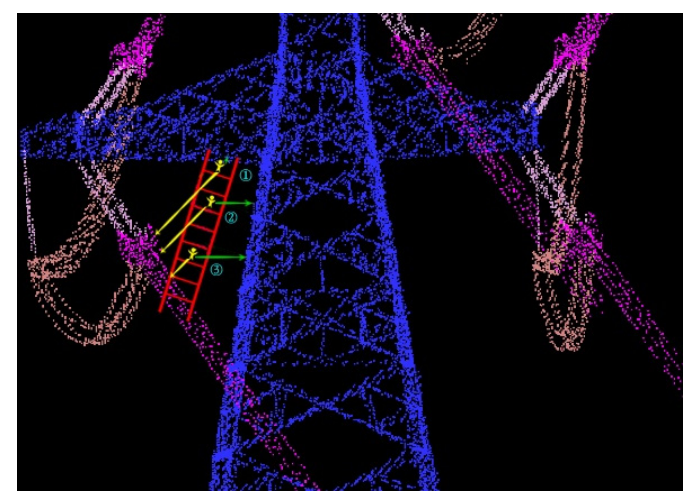

Fig. 6. Flat ladder method enters the electric field interface

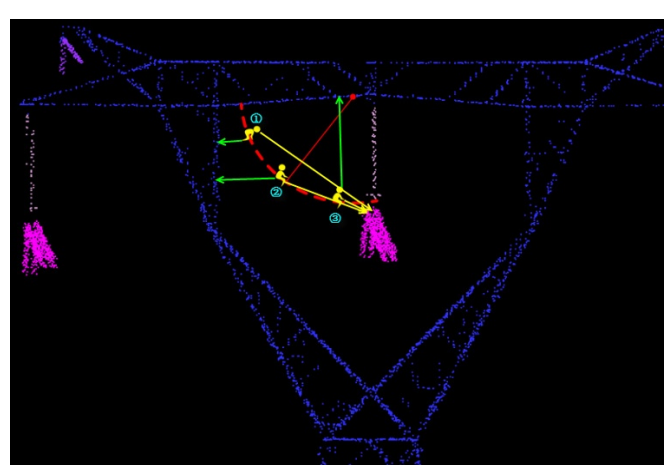

Fig.7. Hanging basket method Going to the electric field interface

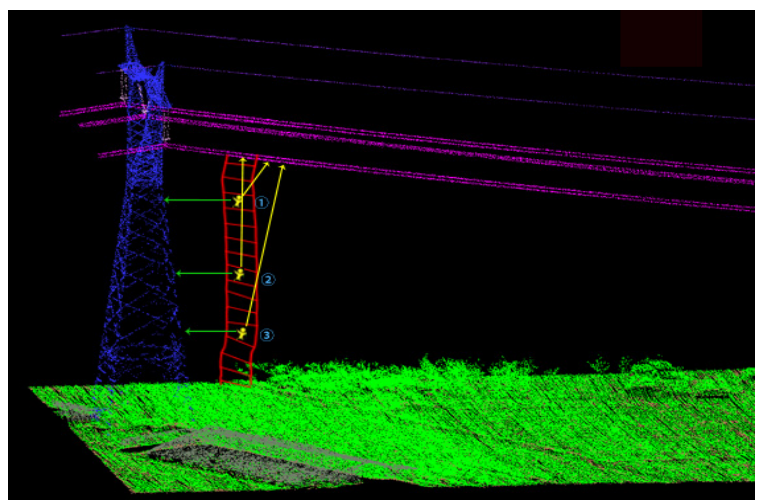

Fig. 8 The ladder method enters the electric field interface

\begin{tabular}{|c|l|c|l|c|l|l|}
\hline & $\begin{array}{l}\text { Wire } \\
\text { model }\end{array}$ & $\begin{array}{l}\text { Breaking } \\
\text { force }(\mathbf{N})\end{array}$ & $\begin{array}{l}\text { Wire } \\
\text { diameter } \\
(\mathbf{m m})\end{array}$ & $\begin{array}{l}\text { Elongation } \\
\text { coefficient }\end{array}$ & $\begin{array}{l}\text { cross- } \\
\text { sectional } \\
\text { area(mm2) }\end{array}$ & $\begin{array}{l}\text { Line } \\
\text { weight } \\
\text { (Kg/Km) }\end{array}$ \\
\hline 1 & LGJ-120/20 & 38950 & 15.07 & 18.90 & 134.49 & 466.80 \\
\hline 2 & LGJ-120/25 & 45480 & 15.74 & 18.50 & 146.73 & 526.60 \\
\hline 3 & LGJ-120/7 & 26190 & 14.50 & 21.20 & 125.50 & 379.00 \\
\hline 4 & LGJ-120/70 & 93450 & 18.00 & 15.30 & 193.40 & 895.00 \\
\hline 5 & LGJ-150/20 & 44290 & 16.67 & 19.60 & 164.50 & 549.00 \\
\hline 6 & LGJ-150/25 & 51400 & 17.10 & 18.90 & 173.11 & 601.00 \\
\hline 7 & LGJ-95/15 & 31587 & 13.61 & 18.90 & 109.72 & 280.00 \\
\hline 8 & LGJ-95/20 & 33572 & 13.87 & 18.50 & 113.96 & 408.90 \\
\hline 9 & LGJ-95/55 & 70494 & 16.00 & 15.30 & 152.81 & 707.70 \\
\hline 10 & LGJ-150/35 & 61760 & 17.50 & 17.80 & 181.62 & 676.20 \\
\hline 11 & LGJ-150/8 & 31210 & 16.00 & 21.20 & 152.80 & 461.40 \\
\hline 12 & LGJ-185/10 & 38830 & 18.00 & 21.20 & 193.40 & 584.00 \\
\hline 13 & LGJ-185/25 & 56440 & 18.90 & 19.60 & 211.29 & 706.00 \\
\hline
\end{tabular}

Fig. 9 Wire parameter interface

\section{Conclusion}

The research and development of this article is to develop a software calculate the electrical and mechanical parameters of live working lines on transmission lines. The feasibility of the operation can be analyzed, and the 
operation tools can be selected reasonably. It can improve the safety and work efficiency of live working, which is of great significance to the majority of live working.

\section{Acknowledgments}

This article was funded by the special scientific research project of the Ministry of Science and Technology of the State Grid Hunan Electric Power Co., Ltd. "The method and equipment for live operation of Qishao Ultra High Voltage, 5216A318000R"

\section{References}

1. W. Xiang Development of Soft Insulating Rod for UHV Live Working. [J]. China Power, 2014 (05): 78-82.

2. Y. Hu, K. Liu. Live work on UHV/UHV AC/DC transmission lines [M].Beijing: China Electric Power Press, 2011.

3. Q/GDW 1799.2-2013 《 State Grid Corporation Electric Power Safety Engineering Regulations Line Part》 [S],2013.

4. DL/T 1242-2013《Technical specifications for live working on $\pm 800 \mathrm{kV}$ DC lines》[S].2013 